\title{
THE SENSITIVITY OF THE MALE GERM CELLS OF DROSOPHILA TO METHYL METHANESULPHONATE
}

\author{
A. J. BATEMAN and A. C. CHANDLEY \\ Paterson Laboratories, Christie Hospital and Holt Radium Institute, Manchester 20
}

\section{INTRODUCTION}

Received I.vi. $6_{4}$

THE mutagenic action of methyl methanesulphonate (MMS) in the male of Drosophila has been studied before. Fahmy and Fahmy (1957, 1961 $a, b$ and $c$ ) included CB I540, which was the Chester Beatty code for MMS, in a series of comparative studies on the "brood patterns " of several mutagens.

Since then several studies have been made on the effects of alkylating agents on fertility and mutation in mammals, including some using MMS (Jackson, et al., I961; Partington, et al., I963, 1964). One of these (Partington and Bateman, I964) was concerned with the induction of dominant lethal mutations in the mouse. In the mouse we know, from the interval between treatment and a given mating, the stage of maturation that the sperm used in that mating had reached at the time of treatment. This is because the time-table of spermatogenesis has been established by Oakberg (1956) and the time taken for the passage of sperm through epididymis and vas deferens has been estimated by Sirlin and Edwards (1957). Thus, one can assess the mutagenic sensitivity of the various stages of maturation. Owing to the apparent difference between the sensitivity pattern for mouse spermatogenesis and that found by Fahmy and Fahmy in Drosophila, it seemed desirable to re-examine the sensitivity of Drosophila germ cells, using refinements now available: daily matings to adequate numbers of females to ensure utilisation of sperm as it matures (e.g. Bateman, ı956; Sävhagen, I96ı), and a recently estimated time-table of spermatogenesis (Chandley and Bateman, 1962).

\section{MATERIALS AND METHODS}

$F_{1}$ hybrid males with high fertility were obtained from the cross between wildtype outbred females (of the "Brum" stock) and $b$ pr vg males. On the first day after emergence they were injected with a constant volume of MMS in saline which had been made up within the hour. The MMS was synthesised in the laboratory by $\mathrm{Dr}$ B. W. Fox and the dilutions were prepared by him. The dose was adjusted by varying the dilution of the solution. The injection into the abdomen was performed with a finely drawn out glass pipette filled to a predetermined mark. The volume of liquid was calculated, from the mean internal cross-section of the pipette multiplied by its length, as $0.092 \mu \mathrm{l}$. (The accuracy of this estimated volume is only of importance for comparison with other published results.) This seemed to us the largest volume the fly could take without leakage out again as a result of the internal 


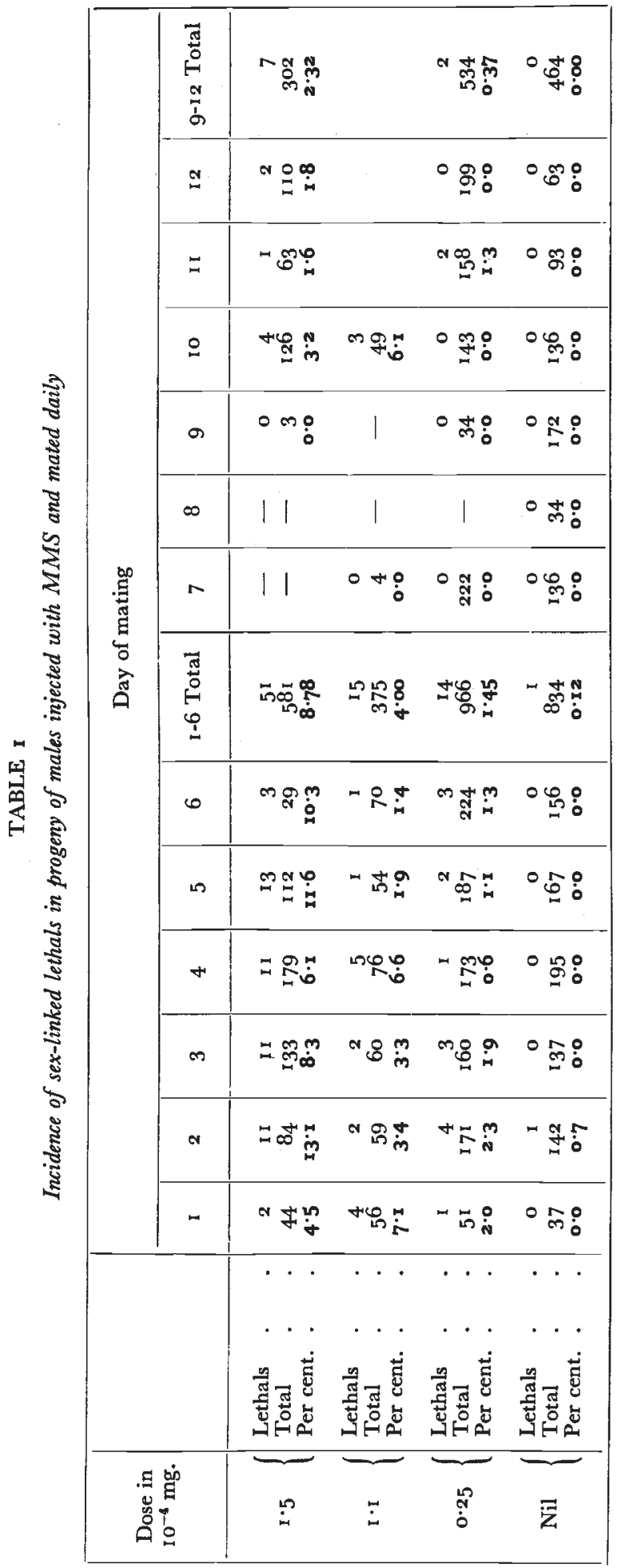


pressure. It represents about one-ninth of the body weight of the male, which is $0.85 \mathrm{mg}$. on average. The dosages, which were varied by dilution of the original solution, ranged in units of $10^{-4} \mathrm{mg}$. from $\mathrm{I} \cdot 5$ through $\mathrm{I} \cdot \mathrm{I}, 0.835$ and 0.5 down to $0 \cdot 25$.

The standard Muller-5 technique was used to identify sex-linked lethals. Injected males were mated individually to two Muller- 5 virgin females every day for 12 days. A lethal was defined as having a viability of less than 2.5 per cent. (i.e. no wild-type males among 40 Muller-5 grandsons). There were four separate runs with a good consistency between runs.

For hatching rates the males were mated individually to two $F_{1}$ untreated females on each day up to day 9 from treatment. The females then laid singly in dominant lethal tubes (see Bateman (1956) for details) for 24 hours and hatching rates were recorded 24 hours later still.

\section{SEX-LINKED LETHALS}

The incidences of sex-linked lethals on successive days of mating are presented in table $\mathrm{I}$. Over the first six days there is no apparent trend in incidence, and the data for these days have been pooled. Over days Io to 12 the incidence is much lower. In between there is a period of complete sterility, the duration varying with dose. The sensitivity of this period to the induction of mutations is therefore not measurable.

During the pre-sterile period the dose-dependence of the mutation rate is approximately linear. According to our time-table of spermatogenesis (Chandley and Bateman, 1962) the first period, with a uniformly high mutation rate, had been treated as sperm and spermatids; the sterile period (days 7 to 9 inclusive) had been treated as spermatocytes; and days Io to I2, with low sensitivity, as spermatogonia.

\section{EGG HATCHABILITY}

The title of this section has been chosen deliberately since the evidence suggests that, in this instance, dominant lethal mutation played only a minor role in depressing the hatching rate of eggs following matings to treated males. Table 2 shows the detailed results, which are summarised graphically in fig. I. The highest dose $\left(\mathrm{I} \cdot 5 \times \mathrm{IO}^{-4} \mathrm{mg}\right.$.) has an effect out of all proportion to the lower doses. The average percentages of unhatched eggs over the first five days of mating are: Control, I.II $; 0.5 \times \mathrm{IO}^{-4} \mathrm{mg} ., 3 \cdot \mathrm{I} 9 ; 0.835 \times \mathrm{IO}^{-4}$ mg., $3 \cdot 12$; and $1 \cdot 5 \times 10^{-4} \mathrm{mg}$., $31 \cdot 33$, which is ten times greater than is produced by over half the dose. Thus there appears to be a threshold effect, which is evidence of a physiological rather than a genetic cause of the depression of hatching rate. Amongst the physiological causes one might expect effects such as interference with the functioning of the sperm, inadequate insemination and infrequent mating. The second and third of these possible defects would be reflected in a lowered rate of egg-laying, for in the hybrid females we used the maximum rate of egg-laying is dependent on insemination. 
No reduction in egg-laying was observed over the first five days. So we conclude that the low hatchability at the highest dose was due to defective sperm leading to the laying of unfertilised eggs.

From day 7 onwards there is a very different effect. Even at the lowest dose $\left(0.5 \times 10^{-4} \mathrm{mg}\right.$. $)$ there is a rise in the proportion of unhatched eggs on day 7 followed by complete failure to hatch on day 8 , whilst at $\mathrm{I} \cdot 5 \times 10^{-4} \mathrm{mg}$. there is almost complete failure to hatch

TABLE 2

Daily variation in egg hatchability at varying doses of $M M S$ to the mated males

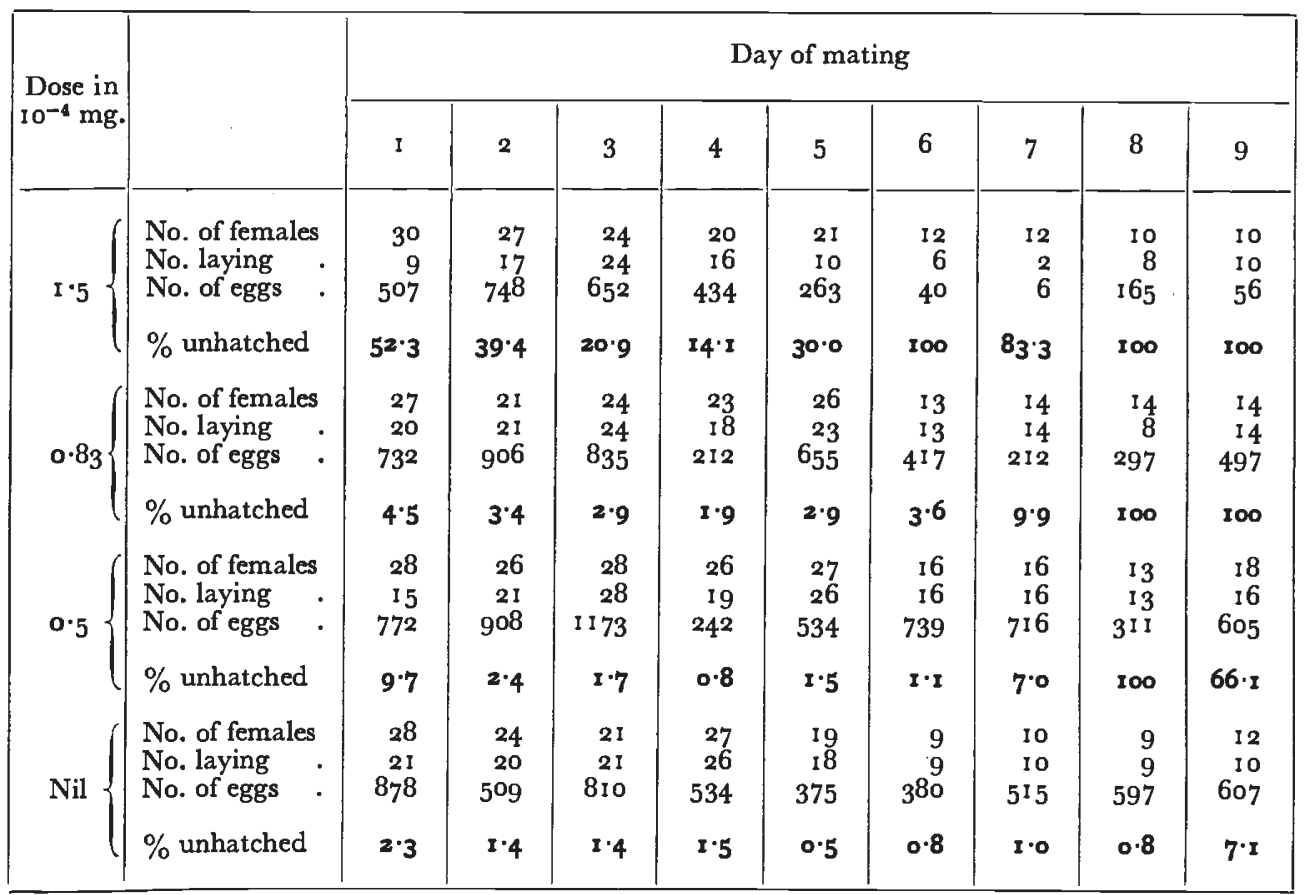

for days 6 to 9 inclusive. Except at the highest dose there is no associated reduction in egg laying. The pattern of sterility up to day 9 is as found in the sex-linked lethal tests. The egg hatching tests were not carried beyond day 9, but the sex-linked lethal tests showed full restoration of fertility from day 10 onwards.

Since the sterility on day 8 was complete at all doses one cannot discuss the dose-dependence, and therefore one cannot argue the relative importance of dominant lethals and other factors in this sterility. However, since egg-laying continued (except at the highest dose) the sterility was not due merely to failure to inseminate.

Summarising the hatchability results, there is a low and constant yield of dominant lethal mutations in matings over the first five days after treatment (treated sperm and spermatids). Superimposed on this is gross malfunction of the sperm at the highest dose, which is greatest 
for treated mature sperm and least for treated spermatids. Treatment of spermatocytes (days 6 to 9 before mating) with $1 \cdot 5 \times 10^{-4} \mathrm{mg}$. produces complete sterility with a high degree of aspermy. Lower doses reveal that the most sensitive stage of spermatocyte is 8 days

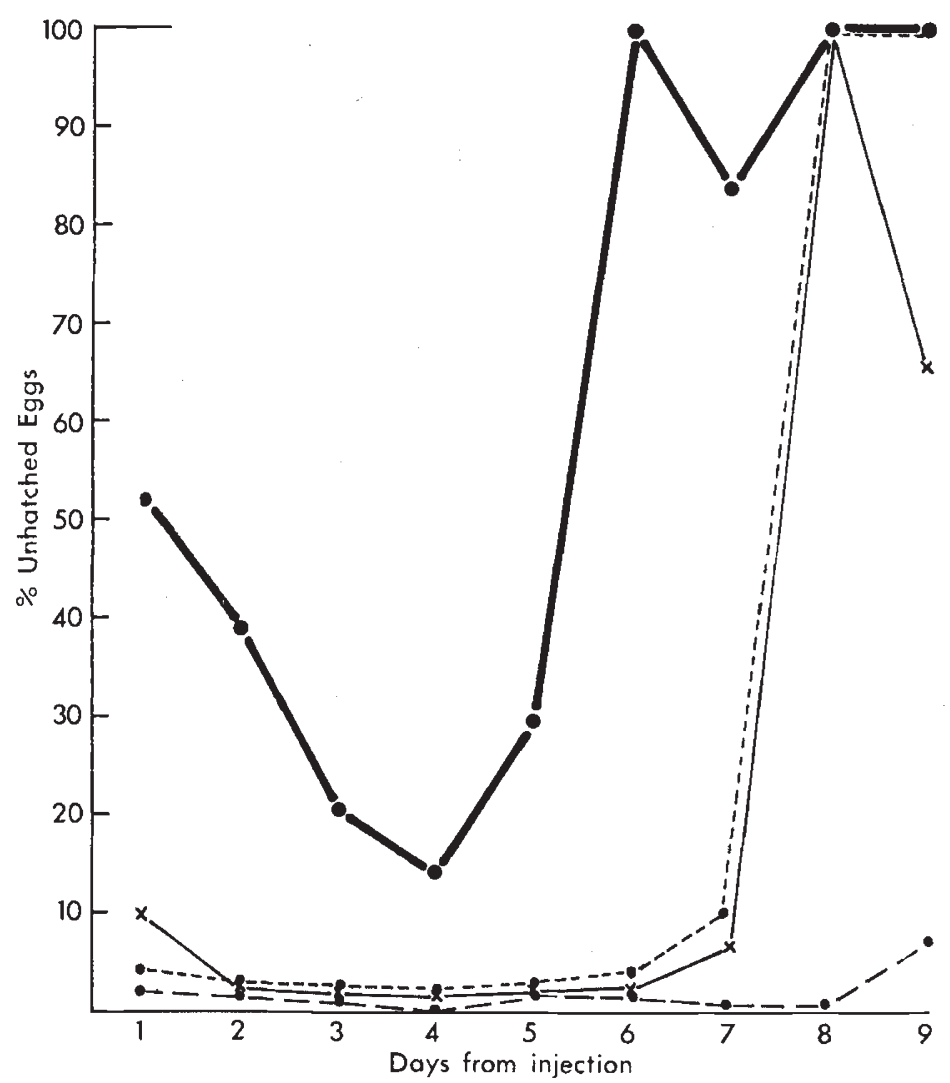

FrG. I.-Effect of MMS at various doses on the hatching rate of eggs laid by females mated to treated males up to nine days after injection.

$$
\begin{array}{lll}
\text { Control } & 0.5 \times 10^{-4} \mathrm{mg} . & 0.83 \times 10^{-4} \mathrm{mg} . \\
\mathrm{I} .5 \times 10^{-4} \mathrm{mg}
\end{array}
$$

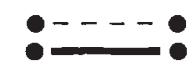

before mating and judging by egg-laying rates, insemination continues throughout the period so that treated spermatocytes must continue to produce sperm, which is malfunctional in some way.

\section{DISCUSSION}

(i) Comparison with $X$-rays

The sensitivity pattern for the production of sex-linked lethals is quite different. X-rayed spermatids produce about three times as many lethals as X-rayed sperm but they have the same sensitivity to MMS. The same comparison would seem to hold for dominant lethals. 
A comparison of the relative rates of dominant and recessive lethals for the two mutagens reveals a major difference. After Iooo rad X-rays the ratio of dominant lethals to sex-linked lethals varies from 3.5 in sperm to 7.0 in spermatids (Chandley and Bateman, 1960). After MMS, however, the rate of induced dominant lethals is not more than the rate for sex-linked lethals excepting the $\mathrm{I}_{5} \times \mathrm{IO}^{-4} \mathrm{mgm}$. dose where other factors must be operating. Using the induction of sexlinked lethals as the standard for comparison Fahmy and Fahmy (1958) found a similar deficiency of dominant lethals with an aminoacid mustard. Their results as well as ours are in agreement with the observations of Auerbach and Robson (1947) that some chemical mutagens, when compared with $\mathrm{X}$-rays, produce less chromosome rearrangements (i.e., breaks) for the same frequency of recessive lethals.

\section{(ii) Comparison with published data}

Fahmy and Fahmy (1957), using MMS (otherwise referred to as CB I540) obtained results which show some striking differences from our own. But first let us deal with resemblances. Their yield of sexlinked lethals was 9.9 per cent. with a solution of $0.45 \times 10^{-2} \mathrm{M}$ in a volume which was variously given as $0.25 \mu \mathrm{l}$ (ibid) and $0.3 \mu \mathrm{l}$ (same authors, 1960). This produces a dose of $\mathrm{I} \cdot 2$ to $\mathrm{I} \cdot 5 \times 10^{-4} \mathrm{mg}$. per fly. Our yield was 8.8 per cent. using $\mathrm{I}^{\circ} 5 \times 1 \mathrm{IO}^{-4} \mathrm{mg}$. in $0.09 \mu \mathrm{l}$. This is excellent agreement, allowing for the preparation of the chemical in different laboratories, its instability, and the origin of the flies from different stocks. The difference between injected volumes is worth noting, however. On average a male of Drosophila melanogaster weighs $0.85 \mathrm{mg}$. when fully hydrated. The volume of mutagen which we injected was therefore one-ninth of the body weight, whereas the Fahmys injected about one-third of the body weight.

Now for the differences. The Fahmys do not record a sterile phase though we found it, of varying duration, at all doses. On the contrary, they analysed numerous progeny during intervals when we failed to obtain any. This might be attributable to a difference in quality of the two preparations of MMS. In our opinion, however, the explanation lies in the different rates of mating the males. The Fahmys supplied each male with one female every three days, in contrast to our regime where each male was mated with two females every day. If sperm utilisation is too slow, some functional sperm will remain in the seminal vesicle, when all those entering from the testis are nonfunctional. Thus fertility would be maintained.

The time sequences are also very different. In the Fahmys' data the high level of mutation rate continued for 4 broods (12 days) and was succeeded at once by a low level for 9 more days. Our high level lasted only 6 days followed by sterility for 3 days and a low level for day ro onwards. Once again the simplest explanation lies in the different rates of sperm utilisation in the two experiments. 


\section{(iii) Comparison with mouse}

If the various germ cell stages of the male mouse showed the same pattern of sensitivity as in Drosophila, MMS would produce the same level of dominant lethals for all matings in the first three weeks (sperm and spermatids at treatment), whereas in fact a detectable amount was found for only one week's duration, from the middle of the first week to the middle of the second week (Partington and Bateman, 1964). This would represent the treatment of sperm in the anterior part of the epididymis and sperm in the seminiferous tubules (not spermatids).

Matings utilising the products of treated mouse spermatocytes (weeks 4 and 5 after treatment) showed no sign of infertility, but histological preparations showed numerous abnormal meioses, yielding abnormal sperm. The damaged spermatocytes evidently succeeded in producing sufficient sperm to maintain full fertility. The absence of dominant lethals from treated spermatogonia has no significance, as $\mathrm{X}$-rays also fail to induce dominant lethals in that stage.

If the high ratio of recessive lethals to dominant lethals with MMS holds for mouse as well as Drosophila, dominant lethal studies will underestimate the mutagenic power of MMS in the mouse. Unfortunately, the mouse is a very unsuitable organism for the study of recessive lethals.

\section{SUMMARY}

Newly emerged males of Drosophila were injected with from $0.25 \times \mathrm{IO}^{-4} \mathrm{mg}$. to $\mathrm{I}^{\cdot} 5 \times \mathrm{IO}^{-4} \mathrm{mg}$. of methyl methanesulphonate (MMS) and mated daily for up to I 2 days.

The rate of sex-linked lethals remained constant for 6 days, after which there was a period of near or complete sterility lasting 3 days, followed by a period with a lower mutation rate.

It is concluded that sperm and spermatids are equally sensitive mutagenically to MMS and spermatogonia are about one-quarter as sensitive. Spermatocytes were sterilised by even the lowest dose, so their mutagenic sensitivity could not be measured.

Except at the highest dose there was little reduction of hatchability of the eggs for the first 5 days, indicating a low yield of dominant lethals. The disproportionate effect of the highest dose on hatchability is attributed to a physiological inhibition of the sperm.

Except at the highest dose, egg-laying continues through the sterility of days 7 to 9 , indicating that the sterility at the lower doses is not due to aspermy.

An attempt is made to resolve the differences between these results and those of earlier publications.

\section{REFERENCES}

AUERBach, C., AND RoBson, J. M. 1947. The production of mutations by chemical substances. Proc. Roy. Soc. Edinb., 62, 271-283. 
bateman, A. J. 1956. Mutagenic sensitivity of maturing Drosophila sperm. I. Dominant lethals. 7. Genetics, 54, 400-410.

ChANDLEY, A. C., AND Bateman, A. J. Ig6o. Mutagenic sensitivity of sperm, spermatids, spermatocytes and spermatogonia in Drosophila melanogaster. Heredity, I5, 363-375.

Chandley, A. C., AND bateman, A. J. 1962. Timing of spermatogenesis in Drosophila melanogaster using tritiated thymidine. Nature, 193, 299-300.

FAHMY, O. G., AND FAHMY, M. J. 1957. Mutagenic response to alkyl-methanesulphonates during spermatogenesis in Drosophila melanogaster. Nature, I80, 31-34.

fahmy, O. G., AND fahmy, M. J. 1958. Discussion on paper by C. Auerbach. Ann. N.Y. Acad. Sci., 68, 736-748.

FAHMY, o. G., AND FAHMY, M. J. 196o. Mutagenicity in the sperm of Drosophila and the structure of the " nitrogen mustard" molecule. Heredity, I5, I I 5-1 78.

FAHMY, O. G., AND FAHMY, M. J. Ig6 $1 a$. Cytogenetic analysis of the action of carcinogens and tumour inhibitors in Drosophila melanogaster. IX. The cell stage response of the male germ line to the mesyloxy esters. Genetics, $46,361-372$.

FAHMY, O. G., AND FAHMY, M. J. $196 \mathrm{I} b$. Cytogenetic analysis of the action of carcinogens and tumour inhibitors in Drosophila melanogaster. X. The nature of the mutations induced by the mesyloxy esters in relation to molecular crosslinkage. Genetics, 46, 447-458.

FAHMY, O. G., AND FAHMY; M. J. 1961c. Cytogenetic analysis of the action of carcinogens and tumour inhibitors in Drosophila melanogaster. XI. Mutagenic efficiency of the mesyloxy esters on the sperm in relation to molecular structure. Genetics, 46, IIII-1 I23.

JACKSON, H., FOX, B. W., AND CRAIG, A. W. 196I. Antifertility substances and their assessment in the male rodent. 7. Reprod. Fertil., 2, 447-465.

OAKBERG, E. G. 1956. Duration of spermatogenesis in the mouse and timing of the cycle of the seminiferous epithelium. Am. F. Anat., 99, 507-5 I6.

PARTington, m., AND Bateman, A. J. 1964. Dominant lethal mutations induced in male mice by methyl methanesulphonate. Heredity, 19, 191-200.

PARTington, M., FOX, B. W., AND JACKson, H. 1964. Comparative action of some methane sulphonic esters on the cell population of the rat testis. Exp. Cell Res., 33, 78-88.

PARTINGTON, M., AND JACKsON, H. Ig63. The induction of dominant lethal mutations in rats by alkane sulphonic esters. Genet. Res., Camb., 4, 333-345.

sÄvHAGEN, R. 196I. The frequency of XO males and induced autosomal crossovers after irradiation of Drosophila melanogaster males in air or commercial nitrogen. Hereditas, 47, 23-42.

SIRLIN, J. L., AND EDWARDS, R. G. 1957. Sensitivity of immature mouse sperm to mutagenic effects of X-rays. Nature, $179,725-727$. 